\title{
The study of causes, mode of delivery in intrauterine fetal death and associated complications
}

\author{
Radhika S. Deshpande*, Manvi M. R.
}

Department of Obstetrics and Gynecology, Kanachur Institute of Medical sciences, Natekal, Karnataka, India

Received: 26 September 2020

Accepted: 31 October 2020

\section{* Correspondence:}

Dr. Radhika S. Deshpande,

E-mail: radhika1187@gmail.com

Copyright: (c) the author(s), publisher and licensee Medip Academy. This is an open-access article distributed under the terms of the Creative Commons Attribution Non-Commercial License, which permits unrestricted non-commercial use, distribution, and reproduction in any medium, provided the original work is properly cited.

\begin{abstract}
Background: Intra uterine fetal death (IUFD) is defined as the baby born with no signs of life at or after 28 weeks of gestation. It is important to diagnose the cause in order to avoid further recurrence and to treat any maternal associated factors. The aim of the present study was to calculate incidence of IUFD in our hospital and know the causes, mode of delivery, associated complications. So we can take measures to prevent them in future.

Methods: The retrospective study was conducted in the department of Obstetrics and Gynecology in Kanachur Medical College, Mangalore from January 2017 to January 2020. The women with confirmed diagnosis of IUFD on Ultrasound and beyond 28 weeks of gestation were included in the study.

Results: In the study period, total 2026 patients delivered, of which 40 cases were IUFD, hence our incidence rate was 19.74 per 1000 population. $62.5 \%$ cases were multigravida. $15 \%$ had previous history of abortions while $5 \%$ previously had IUFD. In $37.5 \%$ cases, the cause was unknown, followed by $22.5 \%$ having pregnancy induced hypertension. Anemia contributed to $17.5 \%$ and placental causes in $12.5 \%$. $10 \%$ of the women had PPH. One patient had sepsis, followed by acute renal failure and later died of multi organ failure.

Conclusions: All the causes are not preventable, many of them can be identified early in pregnancy and thus IUFD can be prevented. All the high risk pregnancies should undergo antenatal fetal surveillance and should have frequent ante natal visits to reduce IUFD rates.
\end{abstract}

Keywords: Anemia, Intra uterine fetal death, Pregnancy-induced hypertension, Stillbirth

\section{INTRODUCTION}

Intra uterine fetal death (IUFD) is defined by WHO as the baby born with no signs of life at or after 28 weeks of gestation. ${ }^{1}$ It is very disappointing news for the patient as well as the doctor, at whatever gestational age it happens. The rate of IUFD and still birth directly point towards the quality of Antenatal Care received by the patient in the society. ${ }^{2}$ In most of the cases, IUFD is unexpected and hence difficult to explain the exact cause of it in many cases.

The definition of IUFD varies in different countries. In UK, IUFD is fetal death after 24 weeks of gestation, while in many states of USA it is after 20 weeks of gestation. ${ }^{3}$ Worldwide over 2.6 million stillbirths happen annually of which $23.2 \%$ were from India. ${ }^{2}$ A vast majority $(98 \%)$ of IUFD occur in developing countries. ${ }^{1}$

It is important to diagnose the cause of IUFD in order to avoid further recurrence and to treat any maternal associated factors. As large number of causes remain unknown, the term "sudden antenatal death syndrome" (SADS) was coined by Cacciature and Collis in 2000. ${ }^{4}$ Most of the intra-partum fetal deaths are associated with obstetric emergencies while stillbirths are associated with maternal infections and diseases. ${ }^{5}$

The major causes responsible for IUFD are illiteracy, lack of prenatal care and limited healthcare system. The 
aim of the present study was to calculate incidence of IUFD in our hospital and know the causes, mode of delivery, associated complications in IUFD cases. So we can take measures to prevent them in future.

\section{METHODS}

The retrospective study was conducted in the department of Obstetrics and Gynecology in Kanachur Medical College, Mangalore from January 2017 to January 2020. The women with confirmed diagnosis of IUFD on Ultrasound, and beyond 28 weeks of gestation were included in the study.

The detailed history of the patient, including obstetric history, past history and present pregnancy events was obtained from the records. Demographic factors and clinical parameters were noted. Also patient's complete investigations, mode of delivery and associated complications were obtained.

The data was analyzed on the basis of cause of IUFD, mode of delivery and associated recurrent causes and complications.

\section{RESULTS}

In the study period, total 2026 patients delivered, of which 40 cases were IUFD, hence our incidence rate is 19.74 per 1000 population. Of 40 IUFD, 14 were booked cases while 26 were unbooked cases as in Table $1.62 .5 \%$ cases were multigravida. $15 \%$ had previous history of abortions while $5 \%$ of the cases previously had IUFD (Table 1).

Table 1: Demographic details.

\begin{tabular}{|lll|}
\hline Detail & Number & Percentage \\
\hline Type of admission & & \\
\hline Unbooked & 26 & 65 \\
\hline Booked & 14 & 35 \\
\hline Parity & & \\
\hline Primigravida & 15 & 37.5 \\
\hline Multigravida & 25 & 62.5 \\
\hline Past obstetric history & & \\
\hline History of abortions & 6 & 15 \\
\hline History of IUFD & 2 & 05 \\
\hline Gestational age & & \\
\hline 28 to 32 weeks & 25 & 62.5 \\
\hline 33 to 37 weeks & 09 & 22.4 \\
\hline 37 to 42 weeks & 06 & 15.1 \\
\hline
\end{tabular}

The maximum cases $(62.5 \%)$ were in gestational age group of 28 to 32 weeks, while only $15 \%$ cases were in gestational age group of more than 37 weeks. $15 \%$ cases were in the age group of less than 20 years and $7.5 \%$ in the age group more than 35 years. This data is more useful as more chances of IUFD occur in teenage pregnancies and elderly patients (Table 2).
Table 2: Maternal age.

\begin{tabular}{|c|c|c|}
\hline Maternal age & Number & Percentage \\
\hline Less than 20 years & 06 & 15 \\
\hline 21 to 25 years & 12 & 30 \\
\hline 26 to 30 years & 14 & 35 \\
\hline 31 to 35 years & 05 & 12.5 \\
\hline More than 35 years & 03 & 7.5 \\
\hline
\end{tabular}

Among total cases, $75 \%$ came with the history of absent fetal movements, while the rest came with labour pains and were diagnosed to have IUFD on noticing absent fetal heart sound on Doppler machine and then confirmed on ultrasound. As in Figure 1, in $37.5 \%$ of the cases, the cause was unknown, followed by $22.5 \%$ having pregnancy induced hypertension (PIH). Anemia contributed to $17.5 \%$ and placental causes in $12.5 \%$ of the total cases.

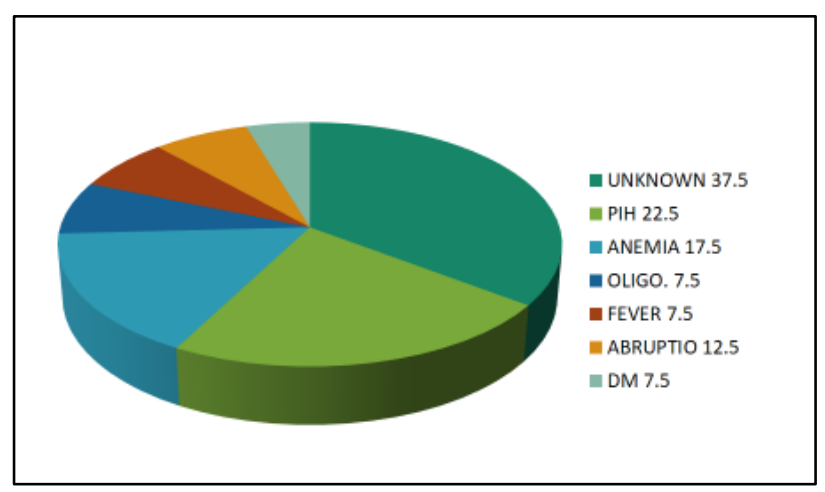

Figure 1: Causes of IUFD.

Of the 40 cases, 10 went into spontaneous labour and delivered vaginally. $10 \%$ of the rest underwent LSCS due to failed induction. In our study, 5\% had obstructed labour and $10 \%$ of the women had PPH. One patient developed DIC followed by acute renal failure, later died of multi organ failure (Table 3 ).

Table 3: Complications of IUFD.

\begin{tabular}{|lll|}
\hline Complications & Number & Percentage \\
\hline Obstructed labour & 02 & 5 \\
\hline PPH & 04 & 10 \\
\hline DIC & 01 & 2.5 \\
\hline Sepsis & 03 & 7.5 \\
\hline ARF & 01 & 2.5 \\
\hline Hysterectomy & 01 & 2.5 \\
\hline Maternal mortality & 01 & 2.5 \\
\hline
\end{tabular}

\section{DISCUSSION}

The total number of deliveries in the study period were 2026. In our study, the majority of cases were unbooked $(65 \%)$ which is similar to study by Jamal et al $(60 \%){ }^{2}$ While number of IUFD was more in booked cases in study by Karle et al. ${ }^{3}$ The incidence of IUFD was $62.5 \%$ 
in multigravida in our study which was also found in the study by Korde-Nayak (51.6\%). ${ }^{6}$ But the rate of IUFD was more in primigravida in study by Desai et al. ${ }^{7}$

The incidence of IUFD was seen more in the age group of 26 to 30 years which is similar to study by Taher et al. ${ }^{1}$ The incidence of IUFD in teenage pregnancy in our study is $15 \%$. The maximum number of IUFD were seen in the gestational age group of 28 to 32 weeks, i.e. $62.5 \%$. Similar incidence was seen in study by Kumari et al $(57.8 \%){ }^{8}$ The rate of IUFD is more in preterm than term pregnancy.

In present study, $75 \%$ of the patients came with absent fetal movements. The study by Jamal et al also noticed $77.1 \%$ cases had absent fetal movements. ${ }^{2}$ The primary contributing cause for IUFD in our study was unknown factors which was similar to study by Desai et al. ${ }^{7}$ Pregnancy induced hypertension (22.5\%) and anemia $(17.5 \%)$ are other common causes of IUFD in our study. Taher et al found pregnancy induced hypertension (PIH) contributing for $17 \%$ of the causes. ${ }^{1} \mathrm{PIH}$ also remains the common cause of IUFD $(41 \%)$ in study by Jamal et al. ${ }^{2}$ Diabetes mellitus and anemia contributed to $7.5 \%$ each in our study, while study by Taher et al showed diabetes mellitus contributing to $9 \%$ of the cases. Other Indian studies had $1.25 \%$ incidence of DM in IUFD. ${ }^{3}$

In our study, Abruption was seen in $12.5 \%$ cases, which was similar to study by Taher et al (12.2\%). Many studies have concluded anemia being the commonest factor for IUFD due to poor compliance to iron tablets. Like gestational diabetes, screening for anemia should be carried out regularly in our patients. This will help us treat patients in time and thus avoid bigger number of IUFD.

The number of complications were less in our study. Two cases had obstructed labour, so underwent emergency cesarean section. One patient with gestational hypertension and abruption developed PPH and underwent obstetric hysterectomy. She developed disseminated intravascular coagulopathy (DIC) and was treated in intensive care unit, given blood products. She later developed sepsis and then acute renal failure. She later succumbed to her illness due to multi-organ failure.

\section{CONCLUSION}

The main intension of the study was to know the causes of IUFD and if they were preventable. Though all the causes are not preventable, many of the causes can be identified early in pregnancy and thus IUFD can be prevented, thus avoiding the trauma to family. All the high risk pregnancies should undergo antenatal fetal surveillance and should have frequent ante natal visits to reduce the rate of IUFD. Sometimes, timely intervention by ante natal steroids, early delivery can give better prognosis for the baby.

\section{Funding: No funding sources Conflict of interest: None declared Ethical approval: Not required}

\section{REFERENCES}

1. Taher FAM, Ali MS. Analytical Study of Intrauterine Fetal Death Cases and Associated Maternal Conditions in Northeast of Libya. IOSR J Nurs Health Sci. 2019;8:67-71.

2. Jamal S, Agarwal S. IUFD incidence, causes and complications: a retrospective study done at a tertiary care centre in greater Noida, India. Int J Reprod Contracept Obstet Gynecol. 2017;6(12):5483-7.

3. Joseph KS, Kinniburgh B, Hutcheon JA, Mehrabadi A, Dahlgren L, Basso $\mathrm{M}$, et al. Rationalizing definitions and procedures for optimizing clinical care and public health in fetal death and stillbirth. Obstet Gynecol. 2015;125(4):784-8.

4. Karale A, Shinde KK, Damle H. Intrauterine fetal demise: a retrospective study in tertiary care center in India. Int J Reprod Contracept Obstet Gynecol. 2018;7(8):1-5.

5. Lawn JE, Blencowe H, Pattinson R, Cousens S, Kumar R, Ibiebele I, et al. Stillbirths: Where? When? Why? How to make the data count? Lancet. 2011;377(9775):1448-63.

6. Korde-Nayak VN, Gaikwad PR. Causes of stillbirth. J Obstetr Gynecol Ind. 2008;58(4):314-8.

7. Desai S, Sawant V. Evaluation of clinical and aetiological factors for intrauterine fetal death. Online Int Interdiscipl Res J. 2014;4(1).

8. Kumari C, Kadam NN, Kshirsagar A, Shinde A. Intrauterine fetal death: A prospective study. J Obstet Gynecol Ind. 2001;51(5):94-7.

Cite this article as: Deshpande RS, Manvi MR. The study of causes, mode of delivery in intrauterine fetal death and associated complications. Int J Reprod Contracept Obstet Gynecol 2020;9:5029-31. 